\title{
Adsorption of the anionic dye methyl orange on used artificial zeolites: kinetic study and modeling of experimental data
}

\author{
Jaouad Bensalah ${ }^{1, *}$, Amar Habsaoui ${ }^{2}$, Brahim Abbou ${ }^{1}$, Lanya Kadiri ${ }^{1}$, Imane Lebkiri ${ }^{1}$, Ahmed Lebkiri ${ }^{1}$ and \\ El Housseine Rifi ${ }^{1}$. \\ ${ }^{1}$ Laboratory of Organic Synthesis and Extraction Process (LSOPE), Department of Chemistry, Faculty of \\ Science, University Ibn Tofail, Kenitra, Morocco \\ ${ }^{2}$ Laboratory Materials and Environmental Engineering Modeling and Application (LMEEMA), Department of \\ Chemistry, Faculty of Science, University Ibn Tofail, Kenitra, Morocco
}

\begin{abstract}
The adsorption of methyl orange (MO) dye by artificial zeolites beads, used previously in the removal of heavy metal through the ionic exchange process, has been studied. The effect of several parameters such as temperature, MO concentration, and zeolite mass on MO adsorption was tested in order to determinate optimal conditions. All results have shown that the adsorption process was influenced by the studied parameters. The kinetic data concerning the study of temperature effect was modeled through pseudo-first-order and pseudosecond-order to determinate the adsorption mechanism. Thermodynamic parameters were calculated using the Van't Hoff equation. Also, they have shown that the studied process has an endothermic, stable and spontaneous nature.
\end{abstract}

Keywords: adsorption; methyl orange; Zeolite; kinetic modeling.

\section{Introduction}

Dyes are widely used in industries such as textile, pulp mills, paper, dye synthesis, food, printing, leather and plastic industries, Nowadays, various kinds of organic dyes are developed and used in leather, electroplating, textile, paper-making, plastics and printing industries ${ }^{1}$, Dyestuffs generally come from the textile, paper, rubber, plastics, paints, printing inks, arts and crafts, leather, food, drugs and cosmetics industries 2. Therefore, developing an efficient technique for the management of the dye industry has long been an essential task for the protection of the environment. Several techniques, including oxidation, ozonation, photochemical degradation, membrane separation, coagulation and adsorption, were employed to eliminate dyes from wastewaters ${ }^{3}$. Adsorption is one of the most effective methods that have been used successfully in this field ${ }^{4-6}$.

Adsorption may be a good option for treating textile effluents since the adsorbent (solid matrix) has many favorable characteristics. Zeolites have an ionic exchange capacity, a negatively charged network and selectivity $7,8,9$. Even with their several advantages, zeolites also have diffusion restrictions for transporting large molecules inside the material ${ }^{10}$. However, recent studies that investigate zeolites properties have proved the important porosity of these materials ${ }^{11}$.

*Corresponding author: Jaouad Bensalah

Email address: bensalahjaouad11@gmail.com

DOI: http://dx.doi.org/10.13171/mjc941911181112jb
Zeolites are crystallized microporous solids belonging to the group of aluminosilicates. The presence of cavities with molecular dimensions and harmful compensation cations induced by the aluminum, gives the zeolites excellent properties leading to many applications, especially in the fields of catalysis, adsorption and cation exchange ${ }^{12}$.

In this work, the methyl orange (MO) dye was selected as a pollutant model to study the adsorption potential of zeolite beads under variation of different experimental conditions, such as temperature, zeolite mass, $\mathrm{MO}$ concentration and $\mathrm{pH}$. Understanding the kinetics of adsorption is a required field for the adsorbents development destined for environmental applications. Therefore, kinetic data were analyzed in order to estimate the adsorption mechanism by pseudo-first-order and pseudo-second-order models. This information may be useful for further studies and practical applications of adsorbent in dyeing wastewater. The thermodynamic study was also effectuated to explain the adsorption process.

\section{Experimental}

\subsection{Materials}

As adsorbent, we used a synthesized used zeolitebased support. Before its application to the treatment of dyed-loaded water, it was first put in contact with a solution of $1 \mathrm{M} \mathrm{HCl}$ in order to purify the support, then

Received October 8, 2019

Accepted November 6, 2019

Published November 18, 2019 
several washing cycles with distilled water were carried out to the neutralization of the adsorbent.

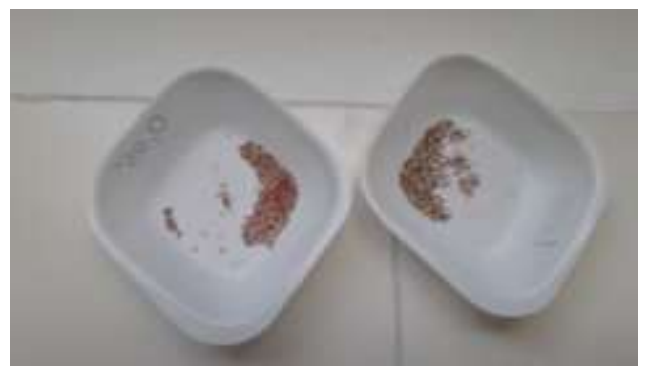

Figure 1. Zeolite beads

\subsection{Preparation of solutions}

Methyl orange $\mathrm{MO}\left(\mathrm{C}_{14} \mathrm{H}_{14} \mathrm{~N}_{3} \mathrm{O}_{3} \mathrm{SNa}\right)$, which has been widely used to simulate organic pollutants in laboratory wastewater ${ }^{13-15,16}$, has been treated in this study. All desired aqueous solutions were prepared by dissolving $1000 \mathrm{mg} . \mathrm{l}^{-1}$ distilled water. The MO dye is very soluble in water. Its characterization was shown in Table 1.

Table 1. Characteristics of Orange Methyl dye

\begin{tabular}{|l|l|l|}
\hline Dye & Chemical structure and formula & Molar mass \\
\hline Methyl Orange MO & & \\
\hline
\end{tabular}

\subsection{Methods}

The adsorption experiments were carried out as a function of the contact time $(0<\mathrm{t}<3 \mathrm{~h})$, the imposed $\mathrm{pH}$ is $\mathrm{pH}=6.5$ on the aqueous solution, the zeolite mass $(0.05 \mathrm{~g}<\mathrm{m}<2 \mathrm{~g})$, the temperature $\left(25^{\circ} \mathrm{C}<\mathrm{T}<55\right.$ $\circ \mathrm{C})$, and the initial dye concentration (10 mg. $\mathrm{l}^{-1}$ $\left.<[\mathrm{MO}]<200 \mathrm{mg} . \mathrm{l}^{-1}\right)$. The tests were carried out by stirring $0.1 \mathrm{~g}$ of zeolites in $100 \mathrm{ml}$ of the synthetic dye solution concentration of $10 \mathrm{mg} \cdot \mathrm{l}^{-1}$. The adsorbent was added to the colored solution until reaching the adsorption equilibrium. The absorbance evolution of contaminated solution was measured using a UV2005 spectrophotometer (CUAE2TI) type UV / visible spectrometer at the wavelength corresponding to the maximum absorbance of orange methyl $(\lambda=468 \mathrm{~nm})$. The residual dye concentration was determined using the calibration curve performed with a known concentration range of MO. The adsorption capacity Qe (mg.g-1) and the removal rate $\mathrm{R}(\%)$ were determined respectively by equations (1) and (2):

$$
\begin{aligned}
& Q e=\left(C_{0}-C_{e}\right) * \frac{V}{m} \\
& R \%=\frac{(\mathrm{C} 0-\mathrm{Ce})}{\mathrm{C} 0} * 100
\end{aligned}
$$

$\mathrm{Co}$ and $\mathrm{Ce}$ are the initial and equilibrium concentrations, respectively, $\mathrm{m}$ is the mass of the support and $\mathrm{V}$ is the volume of the solution.

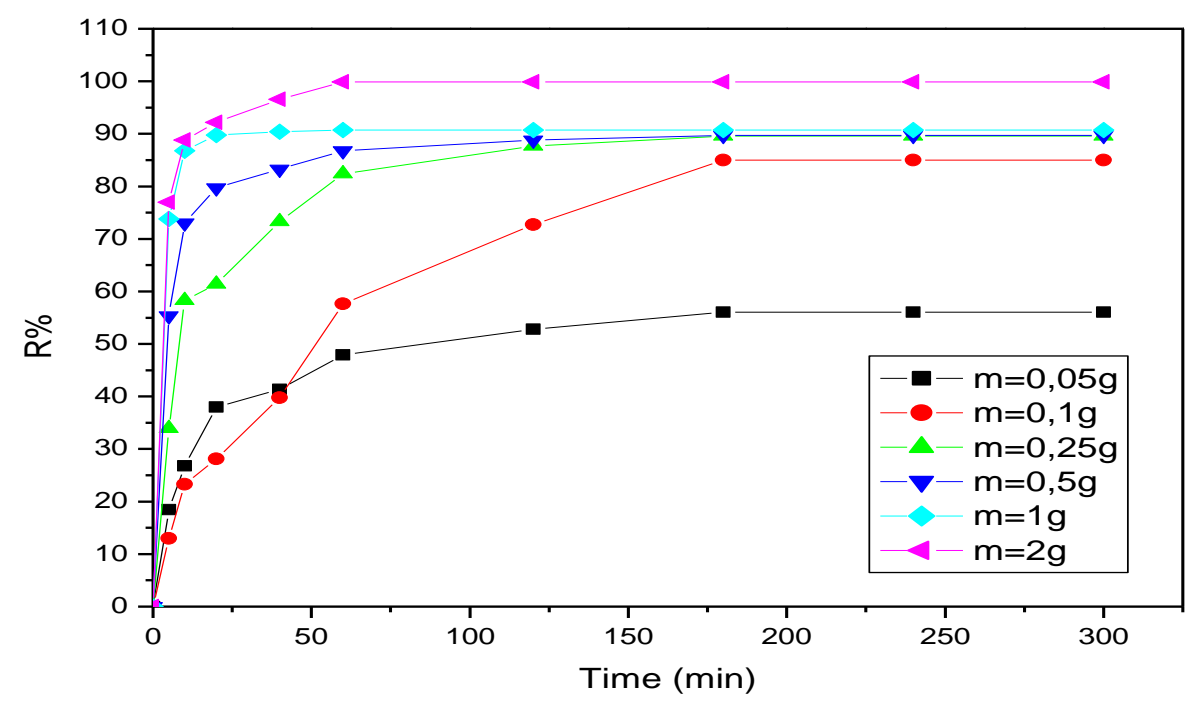

Figure 2. Effect of the mass of zeolite on the adsorption of $\mathrm{MO}\left([\mathrm{MO}]=10 \mathrm{mg} \cdot \mathrm{L}^{-1}, \mathrm{pH}=6.5\right.$ and $\left.\mathrm{T}=298 \mathrm{~K}\right)$

\section{Results and discussion}

\subsection{Effect of zeolite mass on MO adsorption}

To investigate the effect of zeolite mass on MO adsorption, six solutions of $10 \mathrm{mg} . \mathrm{L}^{-1}$, MO were 
mixed with different zeolite quantity ranging from 0.05 to $2 \mathrm{~g}$ for 300 minutes. Figure 2 has shown that the adsorption rate of MO has decreased with the increase of zeolite mass in the aqueous solution. After 180 minutes, the obtained curves have shown that the percentage of removal of the dye (MO) is substantially total (100\%) for a mass of $2 \mathrm{~g}$ zeolite. Such performance of zeolite beads maybe because some adsorption sites were saturated during the adsorption process. It was noted that the adsorption yield of MO increases more rapidly as the mass increases due to the increase in the number of surfaces and reaction sites available for MO adsorption ${ }^{17}$. The mass $0.1 \mathrm{~g}$ of zeolite has given an adsorption yield of the order of $85 \%$; this value was chosen as an optimal mass for economic reasons.

\subsection{Effect of MO concentration on the adsorption process}

Different initial concentrations of $\mathrm{MO}$ were investigated for studying the effect of $\mathrm{MO}$ concentration on the studied process. As shown in Figure 3, the adsorption capacity increases from 8.76 $\mathrm{mg} . \mathrm{g}^{-1}$ to $102.14 \mathrm{mg} . \mathrm{g}^{-1}$ with the increase of initial concentration from $10 \mathrm{mg} . \mathrm{L}^{-1}$ to $200 \mathrm{mg} . \mathrm{L}^{-1}$ of the dye. This result can be attributed to an increase in the driving force of the concentration gradient ${ }^{18}$.

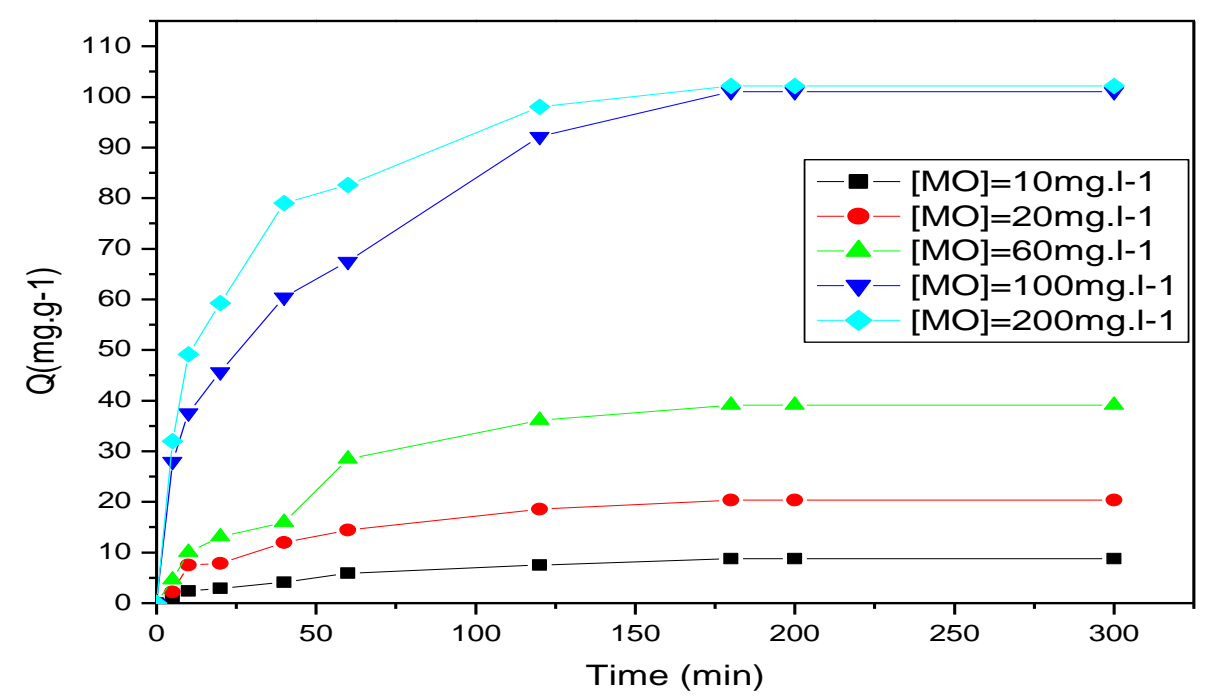

Figure 3. Effect of the concentration on the adsorption of $\mathrm{MO}(\mathrm{m}=0.1 \mathrm{~g}, \mathrm{pH}=6.5, \mathrm{~V}=100 \mathrm{ml}, \mathrm{T}=298 \mathrm{~K})$.

\subsection{Effect of temperature on MO adsorption}

The experiments were performed with the same initial concentration of MO of $10 \mathrm{mg} . \mathrm{L}^{-1}$, with a zeolite dose of $0.1 \mathrm{~g}$ to study the effect of temperature on MO adsorption. Figure 4 has shown that adsorption capacity increases with increasing temperature, which can be attributed to the reaction rate between $\mathrm{MO}$ and zeolite beads increases with temperature. The diffusivity of MO, through the superficial layer of zeolite micropores, also has increased with the increase of temperature, which indicates an endothermic process ${ }^{17}$.

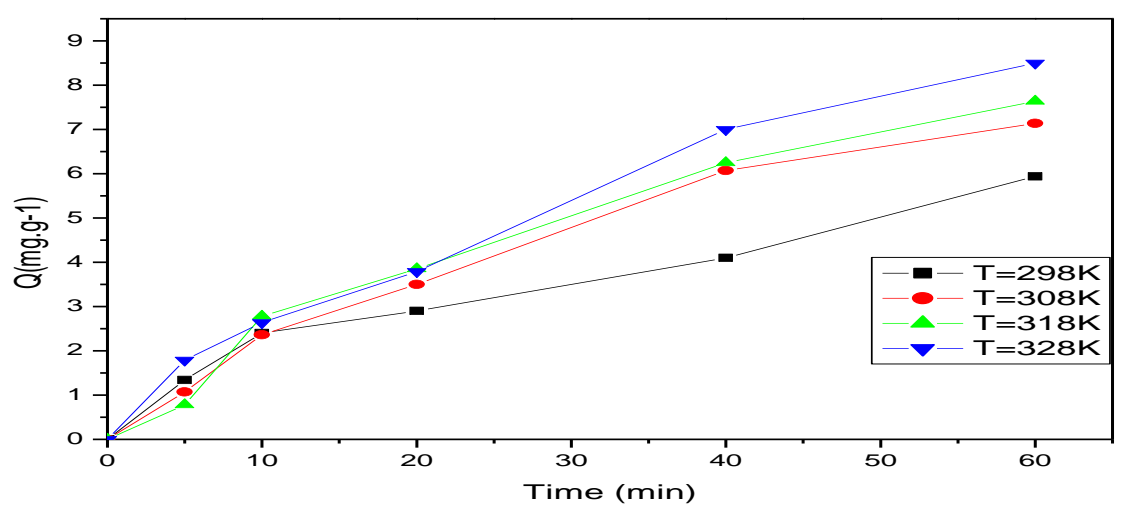

Figure 4. Effect of temperature on the adsorption of $\mathrm{MO}\left(\mathrm{m}=0.1 \mathrm{~g},[\mathrm{MO}]=10 \mathrm{mg} \cdot \mathrm{L}^{-1}, \mathrm{~V}=100 \mathrm{ml}, \mathrm{pH}=6.5\right)$.

\subsection{Thermodynamic Study}

Thermodynamic parameters, including Gibbs free energy change $\left(\Delta \mathrm{G}^{\circ}\right)$, enthalpy change $\left(\Delta \mathrm{H}^{\circ}\right)$ and entropy change $\left(\Delta \mathrm{S}^{\circ}\right)$, are used to evaluate the effect of temperature on adsorption of MO dye on zeolite and provide detailed information about the inherent energy changes associated with the process ${ }^{19}$. The enthalpy $\left(\Delta \mathrm{H}^{\circ}\right)$ and entropy $\left(\Delta \mathrm{S}^{\circ}\right)$ parameters have been estimated from classical relationships: 
$\operatorname{Ln}\left(\mathrm{K}_{\mathrm{L}}\right)=\left(\frac{\Delta \mathrm{S}}{\mathrm{R}}\right)-\left(\frac{\Delta \mathrm{H}}{R}\right)$

$\Delta \mathrm{G}=\Delta \mathrm{H}-\mathrm{T} \Delta \mathrm{S}$

The curve of $\mathrm{LnK}_{\mathrm{L}}$ concerning $1 / \mathrm{T}$ gave a straight line (Fig.5), and the values of $\Delta \mathrm{H}^{\circ}\left(\mathrm{kJ} \cdot \mathrm{mol}^{-1}\right)$ and
$\Delta \mathrm{S}^{\circ}\left(\mathrm{J} \cdot \mathrm{mol}^{-1} \cdot \mathrm{K}^{-1}\right)$ can be calculated from the intersection and slope of these Van 't Hoff plots, respectively. The values of $\Delta \mathrm{G}^{\circ}$ (kJ.mol-1) were recalculated by $\Delta \mathrm{H}^{\circ}$ and $\Delta \mathrm{S}^{\circ}$ (see Table 2). The positive values of $\Delta \mathrm{H}^{\circ}$ have indicated the endothermic nature of the adsorption process

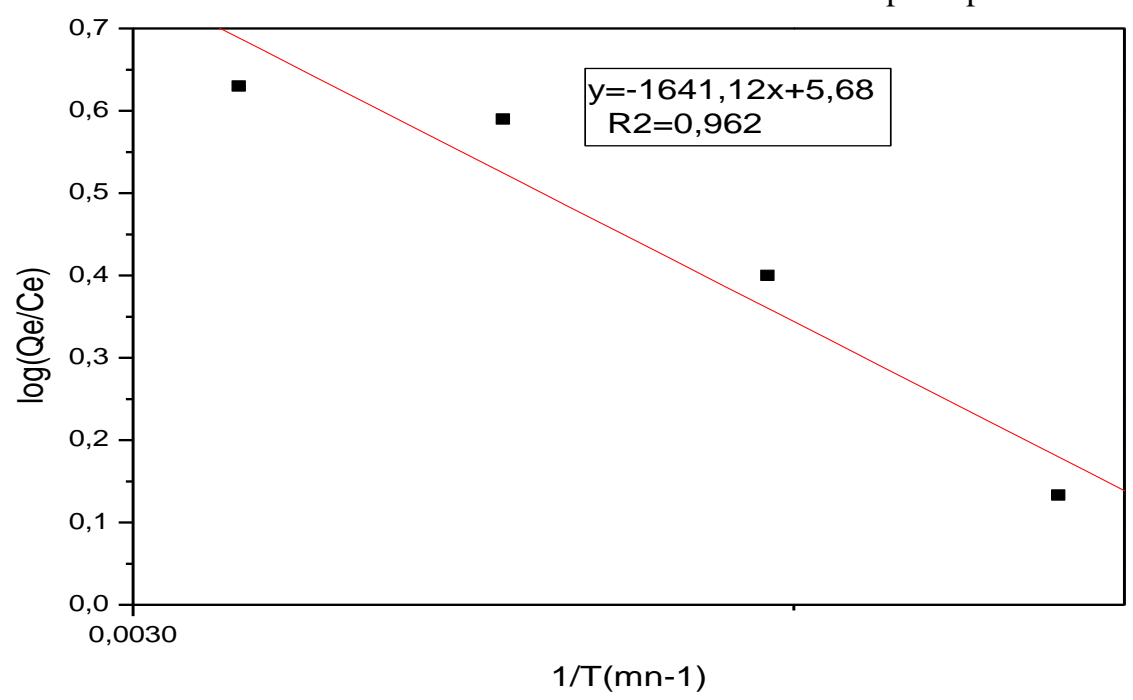

Figure 5. The Van't Hoff plot corresponding to adsorption process

Table 2. Thermodynamic Parameters.

\begin{tabular}{|l|l|l|l|l|l|l|l|}
\hline $\mathrm{T}$ & $1 / \mathrm{T}$ & $\mathrm{Ln}(\mathrm{K})$ & $\mathrm{Qe}$ & $\mathrm{Ce}$ & $\Delta \mathrm{G}^{\circ}\left(\mathrm{Kj}_{\mathrm{mol}}{ }^{1}\right)$ & $\Delta \mathrm{H}^{\circ}\left(\mathrm{Kj}_{\mathrm{mol}}{ }^{1}\right)$ & $\Delta \mathrm{S}^{\circ}\left(\mathrm{J} \cdot \mathrm{mol}^{-1}\right)$ \\
\hline $\mathbf{2 9 8}$ & 0.00335 & 0,133 & 5,94 & 4,37 & $-14,06$ & 13,64 & 47,22 \\
\hline $\mathbf{3 0 8}$ & 0.00324 & 0,40 & 7,14 & 2,83 & $-14,53$ & & \\
\hline $\mathbf{3 1 8}$ & 0.00314 & 0,59 & 7,64 & 1,97 & $-15,00$ & & \\
\hline $\mathbf{3 2 8}$ & 0.00304 & 0,63 & 8,5 & 1,97 & $-15,47$ & & \\
\hline
\end{tabular}

From the thermodynamic point of view, the adsorption was evaluated by the standard values of Gibbs free energy $\left(\Delta \mathrm{G}^{\circ} \mathrm{Kj} . \mathrm{mol}-1\right)$, enthalpy $\left(\Delta \mathrm{H}^{\circ}\right.$ Kj.mol-1) and of the entropy $\left(\Delta \mathrm{S}^{\circ} \mathrm{J} \cdot \mathrm{mol}^{-1}\right)$. All thermodynamic parameters were regrouped in Table 2. The negative values of $\Delta G^{\circ}$ have indicated that adsorption is a spontaneous and favorable process. The positive value of $\Delta \mathrm{H}^{\circ}$ has confirmed that the MO adsorption on the zeolites was an endothermic process of the magnitude and has proved that the studied mechanism of MO adsorption by zeolite beads is physical adsorption (physisorption) ${ }^{20}$.

\subsection{Adsorption Kinetics}

The pseudo-first-order kinetic model ${ }^{21,22}$, describes the adsorption of liquid/solid system. The corresponding equation can be written as:

$\log (q e-q t)=\log q e-\left(\frac{k 1}{2,203}\right) \cdot t$

Where qe and qt are the capacity of the adsorbed metal ions (mg. $\left.\mathrm{g}^{-1}\right)$ at equilibrium and at time $\mathrm{t}(\mathrm{min})$, respectively, and $\mathrm{K} 1$ is the pseudo-first-order rate constant. Thus, the values of qe and $\mathrm{k} 1$ can be determined experimentally by plotting $\log$ (qe-qt) versus $t$ and extracting information from the least- squares slope and intercept and substitution analysis in Eq. (5). Plots log (qe-qt) versus $t$ were shown in Figure 5A. Calculated values of $\mathrm{qe}, \mathrm{k}_{1}$ and the corresponding values of the correlation coefficient of the linear regression $\mathrm{R}^{2}$ were given in Table 2 .

The pseudo-second-order model describes that the adsorption process is controlled by chemisorption, which involves valence forces by electron sharing or exchange between solvent and sorbate. The kinetic model of adsorption is expressed by the following formulation 23,24 :

$\frac{\mathrm{t}}{\mathrm{qt}}=\frac{1}{\mathrm{k} 2 \mathrm{qe} 2}+\frac{\mathrm{t}}{\mathrm{qe}}$

The values of $\mathrm{k}_{2}$ and qe can be calculated from the intercept and the slope of the linear relation, Eq. (6) between $\mathrm{t} / \mathrm{qt}$ and $\mathrm{t}$. The curves of the plotting $\mathrm{t} / \mathrm{qt}$ as a function of $\mathrm{t}$ were given in Figure $5 \mathrm{~B}$, and the calculated values qe, $\mathrm{k}_{2}$, and the corresponding values of the correlation coefficient of the linear regression $\mathrm{R}^{2}$ are summarized in Table 3 .

From the adsorption rate, it can be seen that the pseudo-first-order kinetic model corresponds to the adsorption of MO on zeolites better than the pseudosecond-order model. 

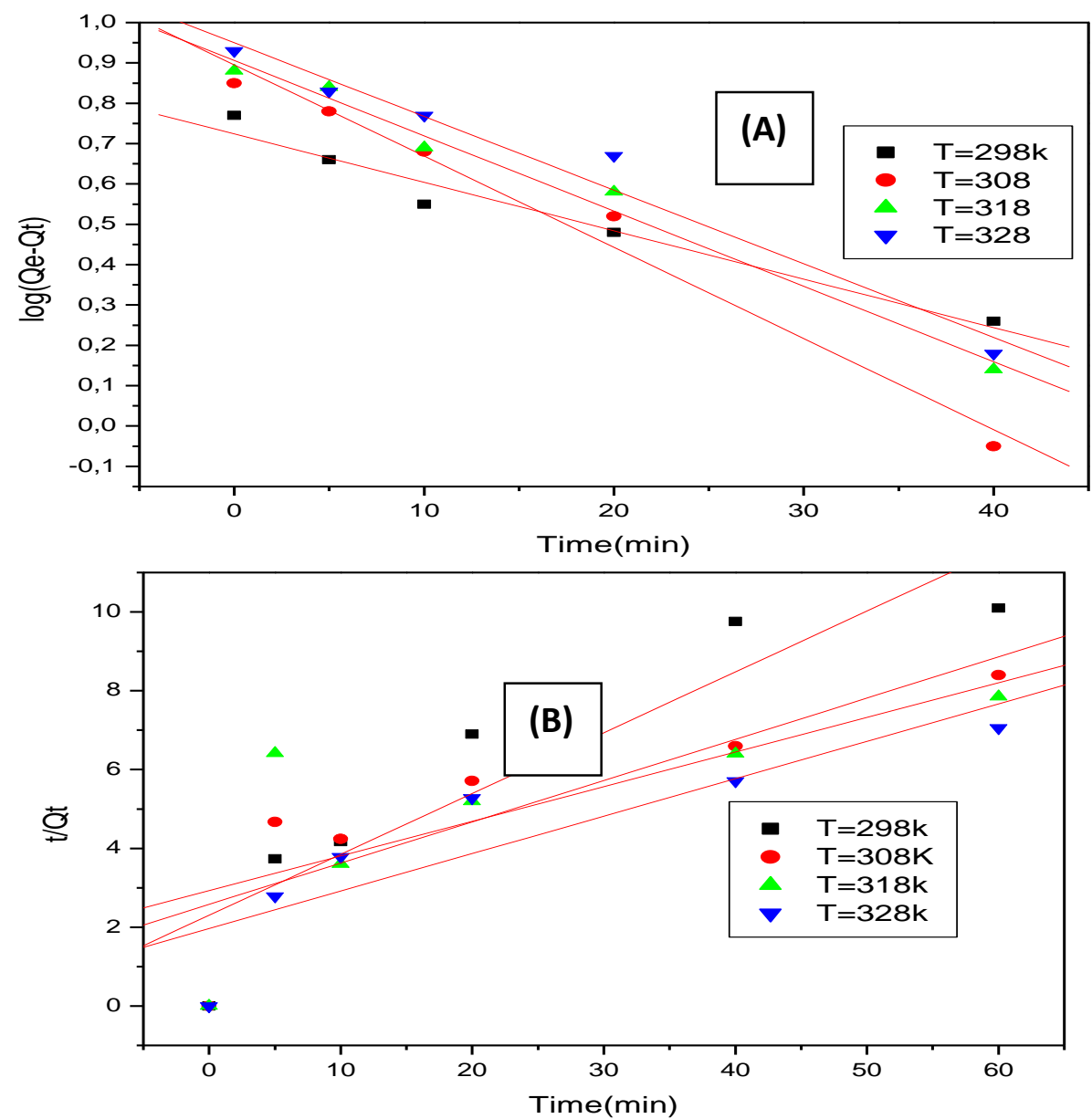

Figure 5. Kinetics of the pseudo-first order (A) and kinetics of the pseudo-second order (B) corresponding to adsorption process $\left(\mathrm{m}=0.1 \mathrm{~g},[\mathrm{MO}]=10 \mathrm{mg} \cdot \mathrm{L}^{-1}, \mathrm{~V}=100 \mathrm{ml}, \mathrm{pH}=6.5\right)$.

Table 3. Parameters of the studied kinetic models.

\begin{tabular}{|l|l|l|l|l|l|l|}
\hline \multicolumn{9}{|c|}{ Pseudo-first order } & \multicolumn{3}{c|}{ Pseudo-second order } \\
\hline $\mathrm{T}$ & $\mathrm{K}_{1}\left(\mathrm{~min}^{-1}\right)$ & $\mathrm{Qe}_{\mathrm{cal}}\left(\mathrm{mg} \cdot \mathrm{g}^{-1}\right)$ & $\mathrm{R} 2$ & $\mathrm{~K}_{2}\left(\mathrm{~g} \cdot \mathrm{mg}^{1} \cdot \mathrm{min}^{-1}\right)$ & $\mathrm{Qe}_{\mathrm{cal}}\left(\mathrm{mg} \cdot \mathrm{g}^{-1}\right)$ & $\mathrm{R} 2$ \\
\hline $\mathbf{2 9 8}$ & 0,026 & 5,30 & 0,982 & 0,010 & 6,49 & 0,918 \\
\hline $\mathbf{3 0 8}$ & 0,045 & 7,85 & 0,988 & 0,0042 & 9,61 & 0,855 \\
\hline $\mathbf{3 1 8}$ & 0,041 & 8,03 & 0,993 & 0,0026 & 11,36 & 0,729 \\
\hline $\mathbf{3 2 8}$ & 0,041 & 8,70 & 0,985 & 0,0049 & 10,52 & 0,879 \\
\hline
\end{tabular}

It was noted that the obtained $\mathrm{R}^{2}$ value using the pseudo-first-order equation is more close to unity (>0.982) in comparison with the pseudo second-order model. The calculated adsorption capacity values (qe cal) ranging from $5.30 \mathrm{mg} \cdot \mathrm{g}^{-1}$ to $8,70 \mathrm{mg} \cdot \mathrm{g}^{-1}$ are close to experimental values ( $\mathrm{qe}_{\exp }$ ) ranging from 5.94 $\mathrm{mg} \cdot \mathrm{g}^{-1}$ to $8.50 \mathrm{mg} \cdot \mathrm{g}^{-1}$. These results have indicated that adsorption kinetics can be described through the pseudo-first-order model. It can be concluded that physisorption is the nature of the $\mathrm{MO}$ adsorption on the adsorbent surface ${ }^{20}$.

\section{Conclusion}

Synthetic zeolite beads have been used as low-cost adsorbents of dyes in aqueous solutions. According to the obtained results in this work, the studied process is influenced by the variation of contact time, adsorbent mass, MO concentration and temperature. Thermodynamic parameters were calculated using the Van't Hoff equation. They have shown that the nature of the studied process is endothermic and spontaneous. Adsorption data were modeled using pseudo-first and second-order kinetic equations. The pseudo-first-order kinetic model could better describe the adsorption kinetics. It can, therefore, be concluded that physisorption is the nature of the MO adsorption on the surface of the zeolite. The experimental results showed that zeolite beads could potentially be used in the removal of the anionic dyes in aqueous solutions and industrial wastewater treatments.

\section{References}

1- M. Tuzen, A. Sari, T.A. Saleh, Response surface optimization, kinetic and thermodynamic 
studies for effective removal of Rhodamine B by magnetic AC/CeO2 nanocomposite, J. Environ. Manage, 2018, 170-177.

2- M.K. Purkait, S. Das Gupta, S. De, Synthesis and adsorption properties of mesoporous material for the removal of dye safranin: Kinetics, equilibrium, and thermodynamics. J. Environ Manage, 2005, 135-142.

3- K.M. Shah, Handbook of Synthetic Dyes and Pigments, 2nd ed, Multitech Publishing Co., India, 1998

4- N. Mohammadi, H. Khani, V.K. Gupta, E. Amereh, S. Agarwal, Adsorption process of methyl orange dye onto mesoporous carbon material-kinetic and thermodynamic studies, $J$. Colloid Inter.f Sci., 2011, 362, 457-62.

5- S.H. Chen, J. Zhang, C.L Zhang, Q.Y Yue, Y. Li, Equilibrium and kinetic studies of methyl orange and methyl violet adsorption on activated carbon derived from Phragmites australis.J. Desalination, 2010, 252, 149-156.

6- A.S. Tawfik, K.G.Vinod, Photo-catalyzed degradation of hazardous dye methyl orange by use of a composite catalyst consisting of multiwalled carbon nanotubes and titanium dioxide, J. Colloid Interf Sci.,2012, 371, 101-6.

7- H. Aysan, S. Edebali, C. Ozdemir, M.C. Karakaya, N. Karakaya, Use of chabazite, a naturally abundant zeolite, for the investigation of the adsorption kinetics and mechanism of methylene blue dye, J. Microporous and Mesoporous Materials., 2016, 235, 78-86.

8- C. Perego, R. Bagatin, M. Tagliabue, R. Vignola, Zeolites and related mesoporous materials for multi-talented environmental solutions, J. Microporous and Mesoporous Materials, 2013, 166, 37-49.

9- R. Garima, A. Amardeep, S. Damini, T. Ravi, T. Vartika, C. Ramesh. A new biocompatible ternary Layered Double Hydroxide Adsorbent for ultrafast removal of anionic organic dyes, Scientific Reports, 2019.

10- J. Perez-Ramirez, C.H. Christensen, K. Egeblad, C.H. Christensen, J.C. Groen, Hierarchical zeolites: enhanced utilisation of microporous crystals in catalysis by advances in materials design, J. Chem. Soc. Rev, 2008, 37, 2530-2542.

11-A. Feliczak-Guzik, Hierarchical zeolites: synthesis and catalytic properties, J. Microporous and Mesoporous Materials, 2018, 259, 33-45.

12-A. Said, L. Limousy, H. Nouali, L. Michelin, J. Halawani, J. Toufaily, T. Hamieh, P. Dutournié, T. Jean Daou, Synthesis of mono- and bi-layer MFI zeolite films on macroporous alumina tubular supports: Application to nanofiltration, Journal of crystal growth, 2015, 71-79.
13- M.M. Khan, J. Lee, M.H. Cho, Au@TiO2 nanocomposites for the catalytic degradation of methyl orange and methylene blue: an electron relay effect, J. Ind. Eng. Chem., 2014, 1584-1590.

14- X. An, C. Gao, J. Liao, X. Wu, X. Xie, Synthesis of mesoporous N-doped TiO2/ ZnAl-layered double oxides nanocomposite for efficient photodegradation of methyl orange, Mater, Sci. Semicond. Process, 2015, 34, 162-169.

15- D. Ljubas, G. Smoljanic', H. Juretic', Degradation of Methyl Orange and Congo Red dyes by using $\mathrm{TiO} 2$ nanoparticles activated by the solar and the solar-like radiation, J. Environ. Manage, 2015, 83-91.

16-F.Z. Mahjoubi, A. Khalidi, A. Elhalil, N. Barka, Characteristics and mechanisms of methyl orange sorption onto $\mathrm{Zn} / \mathrm{Al}$ layered double hydroxide intercalated by dodecyl sulfate anion, Scientific African, 2019.

17- H.S. Zhu, X.J. Yang, Y.P. Mao, Y. Chen, X.L. Long, W.K. Yuan, Adsorption of EDTA on activated carbon from aqueous solutions, $J$. Hazard Mater, 2011, 951-957.

18- Y.J. Yao, B. He, F.F. Xu, X.F. Chen, Equilibrium and kinetic studies of methyl orange adsorption on multiwalled carbon nanotubes, $J$. Chem. Eng., 2011, 170, 82-9.

19- T. Ngulube, R. Gumbo, J. Masindi, V. Maity, An update on synthetic dyes adsorption onto claybased minerals: a state-of-art review, J. Environ. Manag., 2017, 191,35-57.

20-G.V. Brião, L. S. Jahn, E.L. Foletto, G.L. Dotto, Highly efficient and reusable mesoporous zeolite synthetized from a biopolymer for cationic dyes adsorption, J. Colloids and Surfaces A, 2018, 556, 43-50.

21- C.L. Chen, X.K. Wang, Adsorption of Ni(II) from aqueous solution using oxidized multiwall carbon nanotubes, Ind Eng Chem.Res., 2006, 9144-9149.

22- S.T. Yang, J.X. Li, D.D. Shao, J. Hu, X.K. Wang, Adsorption of Ni(II) on oxidized multiwalled carbon nanotubes: effect of contact time, $\mathrm{pH}$, foreign ions and PAA, J. Hazard Mater.,2009, 109-116.

23- D.L. Zhao, G.D. Sheng, J. Hu, C.L. Chen, X.K. Wang, The adsorption of $\mathrm{Pb}$ (II) on $\mathrm{Mg} 2 \mathrm{Al}$ layered double hydroxide, J. Chem Eng., 2011,167-174.

24-X.L. Tan, X.K. Wang, H. Geckeis. T.H. Rabung, Sorption of Eu(III) on humic acid or fulvic acid bound to alumina studied by SEMEDS, XPS, TRLFS and batch techniques, J. Environ Sci. Technol., 2008, 6532-6537. 